\title{
Blood serum levels of proinflammatory cytokines in patients with different degrees of biliary pancreatitis
}

\author{
Józefa Panek MD PhD¹, Danuta Karcz MD PhD ${ }^{1}$, Richard Pieton MD PhD², Jakub Zasada MD, \\ Marcin Tusinski MD¹, Miroslaw Dolecki MD¹, Marek Winiarski MD ${ }^{1}$
}

\begin{abstract}
J Panek, D Karcz, R Pieton, et al. Blood serum levels of proinflammatory cytokines in patients with different degrees of biliary pancreatitis. Can J Gastroenterol 2006;20(10):645-648.
\end{abstract}

BACKGROUND: Proinflammatory cytokines play a fundamental role in the local and systemic inflammatory responses in the initial stages of acute biliary pancreatitis (ABP) and in the development of severe forms of the disease.

OBJECTIVES: The aim of the present study was to assess the systemic release of proinflammatory cytokines and to characterize differences between patients with mild ABP (MABP) and severe ABP (SABP)

PATIENTS AND METHODS: In the current study, 54 patients with MABP were compared with 14 patients with SABP. Serum levels of tumour necrosis factor-alpha, interleukin (IL)-1 $\beta$, IL-6, IL-8 and IL-12p40 were measured every second day after admission for one week. RESULTS: The tumour necrosis factor-alpha level was similar in all days of analysis in patients with MABP but was lower compared with SABP patients. The level of IL-1 $\beta$ was higher at admission in patients with MABP. The level of IL-6 peaked on admission day in both groups, but in patients with SABP, the obtained values were higher. The level of IL-8 on admission day was slightly higher in patients with MABP and systematically decreased when measured on the following days (the third, fifth and seventh days of the study). An increased level of IL-8 during the third, fifth and seventh days of the investigation was seen in SABP patients. The level of IL-12p40 was slightly higher in patients with MABP on the day of admission.

CONCLUSIONS: The levels of some proinflammatory cytokines are higher in patients with SABP than in patients with MABP. The most consistent difference between the two groups was that the levels of IL-6 were significantly higher in patients with SABP throughout the study. Serum concentration of IL- 6 may be helpful as a marker of severity and outcome of ABP.

Key Words: Acute biliary pancreatitis; Interleukins

\section{Les taux de sérum sanguin des interleukines pro-inflammatoires che $z$ des patients atteints de pancréatite biliaire de gravités variées}

\begin{abstract}
HISTORIQUE : Les cytokines pro-inflammatoires jouent un rôle fondamental dans les réponses locales et systémiques au cours des premières phases de la pancréatite biliaire aiguë et dans l'évolution des formes graves de la maladie.

OBJECTIFS : La présente étude visait à évaluer la libération systémique de cytokines pro-inflammatoires et à caractériser les différences entre les patients atteints de pancréatite biliaire aiguë bénigne (PBAB) et ceux atteints de pancréatite biliaire aiguë grave (PBAG).

PATIENTS ET MÉTHODOLOGIE : Pendant l'étude, 54 patients atteints de PBAB ont été comparés à 14 patients atteints de PBAG. Les taux sériques de facteur de nécrose tumorale alpha, d'interleukine (IL)-1 $\beta$, IL-6, IL-8 et IL-12p40 ont été mesurés tous les deux jours après une hospitalisation d'une semaine.

RÉSULTATS : Le taux de facteur de nécrose tumorale alpha était semblable tous les jours d'analyse chez les patients atteints de PBAB, mais plus faible que chez les patients atteints de PBAG. Le taux d'IL-1 $\beta$ était plus élevé à l'hospitalisation chez les patients atteints de PBAB. Le taux d'IL-6 a atteint son point culminant le jour de l'hospitalisation dans les deux groupes, mais chez les patients atteints de PBAG, les valeurs étaient plus élevées. Le taux d'IL-8 à l'hospitalisation était légèrement plus élevé chez les patients atteints de PBAB et a diminué systématiquement lors des mesures suivantes (les troisième, cinquième et septième jours de l'étude). Un taux plus élevé d'IL-8 les troisième, cinquième et septième jours de l'étude a été constaté chez les patients atteints de PBAG. Le taux d'IL-12p40 était légèrement plus élevé le jour de l'hospitalisation chez les patients atteints de PBAB.

CONCLUSIONS : Le taux de certaines cytokines pro-inflammatoires est plus élevé chez les patients atteints d'une PBAG que chez ceux qui souffrent d'une PBAB. Tout au long de l'étude, le taux d'IL-6 est demeuré considérablement plus élevé chez les patients atteints d'une PBAG, ce qui constitue la principale différence entre les deux groupes. La concentration sérique d'IL-6 pourrait constituer un marqueur utile de la gravité et de l'issue de la pancréatite biliaire aiguë
\end{abstract}

$\Lambda$ cute biliary pancreatitis (ABP) is a disease of diverse Aclinical manifestations. In $80 \%$ to $85 \%$ of cases, we observe a clinically mild ABP (MABP), pathologically identical to interstitial (edematous) ABP. Complications of $\mathrm{MABP}$ are rare and the mortality rate is low. In the remaining $15 \%$ to $20 \%$ of patients who have severe ABP (SABP), there are extensive necrotic changes within the pancreatic gland as well as in the fatty tissue of the peripancreatic retroperitoneal space. In approximately $40 \%$ to $70 \%$ of severe cases, the disease progresses into infection of the necrotic pancreatic tissue. The infection results in death in $20 \%$ to $40 \%$ of patients $(1,2)$. Patients with SABP develop life-threatening complications, usually in the form of multiple organ dysfunction syndrome (MODS).

Pathophysiological changes occurring in the course of ABP have not yet been fully explained. The clinical role and significance of cytokines in the development of ABP have been documented in recent years in numerous experimental and

${ }^{1}$ Second Department of Surgery, Collegium Medicum of Jagiellonian University, Kraków, Poland; ${ }^{2}$ West Los Angeles Veterans Affairs

Medical Center, Los Angeles, California, USA

Correspondence: Dr Józefa Panek, II Katedra Chirurgii Collegium Medicum Uniwersytetu Jagiellonskiego, ul. Kopernika 21,

31-501 Kraków, Poland. Telephone 481-242-48201, fax 481-242-13456, e-mail mspanek@cyf-kr.edu.pl

Received for publication June 28, 2005. Accepted February 20, 2006 
TABLE 1

\section{Patient characteristics}

\begin{tabular}{lcc}
\hline & MABP & SABP \\
\hline Number of patients & 54 & 14 \\
Mean age in years (range) & $58(24-88)$ & $59(47-80)$ \\
Sex (male/female) & $16 / 38$ & $4 / 10$ \\
Mean APACHE II score (points) & 1,27 & 14,33 \\
Mean Ranson's criteria (score) points & 1,52 & 4,21 \\
Computed tomography grade & & \\
$\quad$ Baltazar score (A - E) & $21(\mathrm{~A})$ & $3(\mathrm{C})$ \\
& $33(\mathrm{~B})$ & $6(\mathrm{D})$ \\
& & $5(\mathrm{E})$ \\
\hline
\end{tabular}

APACHE Acute Physiology and Chronic Health Evaluation; MABP Mild acute biliary pancreatitis, SABP Severe acute biliary pancreatitis

clinical studies (3-16). Cytokines may induce systemic inflammatory response syndrome which can progress to MODS, multiple organ failure and, finally, death.

According to a recent hypothesis, overstimulation of the white blood cell system could be responsible for this kind of response (3). Alcohol and biliary stones are the two most common causes of ABP.

The aim of the present study was to compare cytokine responses between patients with different degrees of severity of ABP.

\section{PATIENTS AND METHODS}

Fifty-four patients with MABP and 14 with SABP were included in the study. All patients with SABP underwent computed tomography $(\mathrm{CT})$ scanning. In a few cases, the CT scan was performed more than once. For each patient, the diagnosis of ABP was established based on clinical history, ultrasonography (USG) examinations and serum amylase activity (at least three times above the reference limit). All patients enrolled in the study were hospitalized within $24 \mathrm{~h}$ of appearance of their clinical symptoms. Patient characteristics are shown in Table 1. The etiology of ABP was determined based on the clinical history and the presence of stones in the gallbladder or in the common bile duct. The progression of morphological changes within the pancreas was evaluated using USG and the Becker scale (17). Each patient had USG examinations performed every day during the study period. It allowed for the analysis of the evolution of inflammatory changes within the gland and the surrounding areas.

The CT scans showed an evolution in necrotic changes of the parenchyma of the gland and in the retroperitoneal and peritoneal spaces. The Balthazar score was used for this evaluation (18). The severity of $\mathrm{ABP}$ was determined according to clinical and laboratory parameters. ABP classification met the Atlanta criteria (19), Ranson's criteria (20), and Acute Physiology and Chronic Health Evaluation (APACHE II) score (21). The degree of organ dysfunction was measured using the MOD score (22).

Blood samples were taken from each patient on the first, third, fifth and seventh days of the study, to determine the levels of proinflammatory cytokines such as tumour necrosis factor-alpha (TNF- $\alpha$ ), interleukin (IL)-1 $\beta$, IL-6, IL-8 and IL-12p40. ELISA kits (BioSource International Inc, USA) were used to measure the cytokine levels.

\section{Statistics}

The data were analyzed with two-way factorial ANOVA model with repeated measures. The studied factors were group (SABP

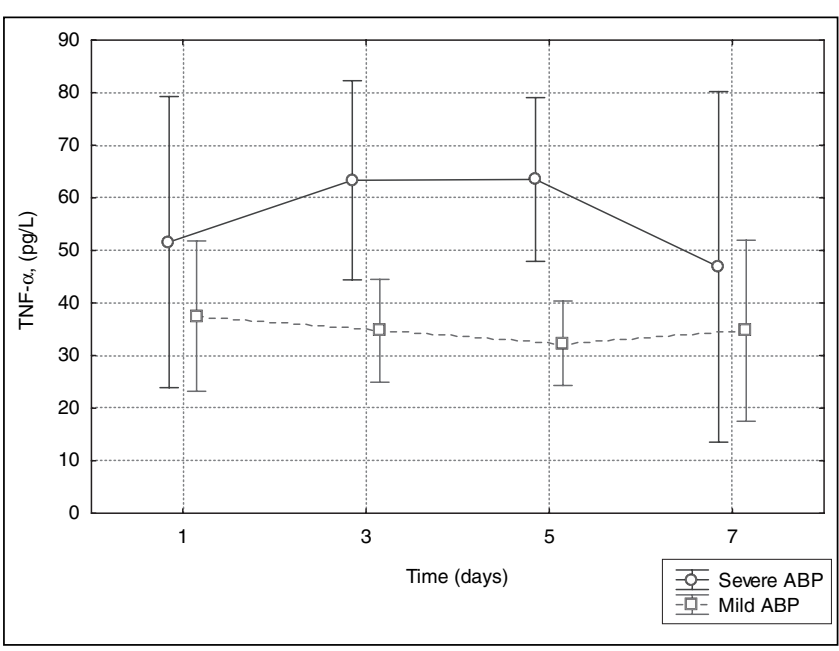

Figure 1) Serum levels of tumour necrosis factor-alpha (TNF- $\alpha)$ in patients with mild and severe acute biliary pancreatitis (ABP)

versus $\mathrm{MABP}$ ) and time (four measurements taken every two days). The influence of time was assessed by assuming a linear trend. The analysis consisted of two steps. First, all data were included and possible outliers were identified for subsequent removal for the final analysis. An observation was skipped if the value of its standardized residual was greater than 3.5. The output of the second step, which is the proper analysis, is presented in the results.

No differences in average age of patients from the two studied groups were found $\left(\mathrm{F}_{1,73}=0.41, \mathrm{P}=0.5248\right)$. Nevertheless, one could prefer to estimate the influence of the form of pancreatitis on the condition of the immune system having controlled for age. Including this variable in a model hardly changed the conclusions, so a more parsimonious model was used.

\section{RESULTS}

The mean level of TNF- $\alpha$ was higher in patients with necrotizing pancreatitis (SABP) than in patients with MABP $\left(\mathrm{F}_{1,17}=7.73, \mathrm{P}=0.0126\right)$. There was no statistically significant change in the mean levels of TNF- $\alpha$ during the study time between the groups of patients. Interaction of the linear trends was also not statistically significant. The shape of the dynamics of the mean levels of TNF- $\alpha$ suggested the curvilinear course of this process. Therefore, in this case, the fitting of the square trend was checked. Statistical significance of this fitting did not lie in the critical area of this test. Because of the short series of measurements (patients were examined only four times) it was not possible to perform the test of interactions of the square trends (Figure 1).

No statistically significant difference was found in the concentration of IL-1 $\beta$ between the groups of patients with SABP versus MABP. There was also no change in the concentration of IL-1 $\beta$ over time between the groups of patients. The differences in the concentration of IL- $1 \beta$ between the two groups of patients on the following days of study were also not statistically significant (Figure 2).

In patients with necrotizing pancreatitis, the concentration of IL- 6 was higher than in the group with the edematous form of the disease $\left(F_{1,41}=16.45, P<0.001\right)$. In both groups, the concentration of IL- 6 decreased over time (the group with SABP: $\mathrm{F}_{1,41}=7.18, \mathrm{P}=0.0106$; the group with MABP: $\mathrm{F}_{1,41}=5.47$, 


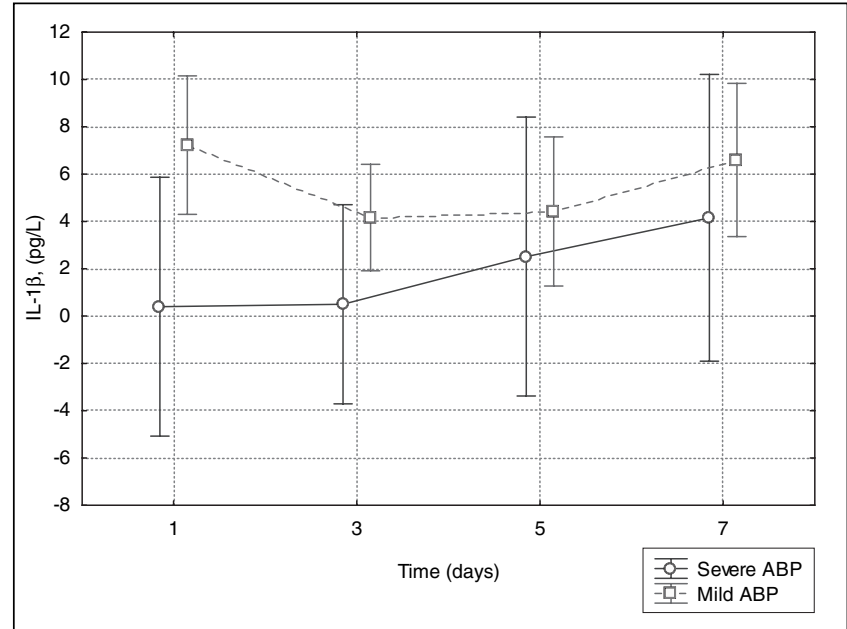

Figure 2) Serum levels of interleukin (IL)-1 $\beta$ in patients with mild and severe acute biliary pancreatitis (ABP)

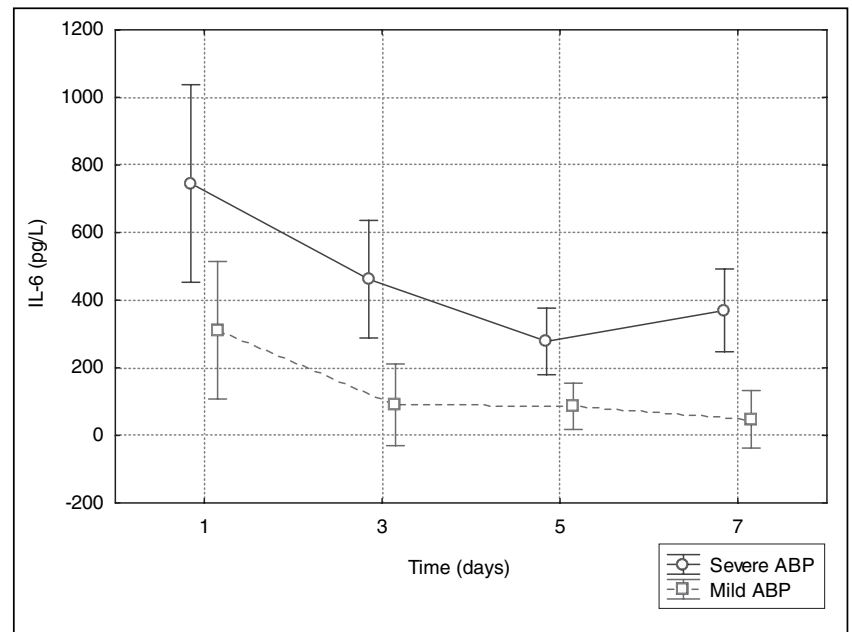

Figure 3) Serum level of interleukin (IL)-6 in patients with mild and severe acute biliary pancreatitis $(\mathrm{ABP})$

$\mathrm{P}=0.0243)$. The statistical analysis did not indicate that the differences in mean concentrations of IL- 6 between groups depended on time $\left(\mathrm{F}_{1,41}=0.75, \mathrm{P}=0.3915\right)$ (Figure 3$)$.

The mean concentration of IL- 8 was higher in the group with necrotizing pancreatitis than in the group with the edematous form of the disease $\left(\mathrm{F}_{1,47}=4.03, \mathrm{P}=0.0502\right)$. The mean level of IL- 8 in the third, fifth and seventh days of the study seemed to increase in patients with SABP $\left(\mathrm{F}_{1,48}=3.32\right.$, $\mathrm{P}=0.0749)$ and decrease in patients with $\mathrm{MABP}\left(\mathrm{F}_{1,48}=6.20\right.$, $\mathrm{P}=0.0161$ ). In the first day of hospitalization the mean concentration of IL-8 in both groups of patients was similar. But in the next days of the study, the mechanism of dynamics of this parameter caused higher values in the group with SABP (interaction of linear trends: $\mathrm{F}_{1,48}=8.05, \mathrm{P}=0.0066$ ) (Figure 4).

No statistically significant differences between mean levels of IL-12p40 and changes over time of IL-12p40 between the groups of patients were observed. There was also no difference in concentration of IL-12p40 between groups of patients in correlation with time (Figure 5).

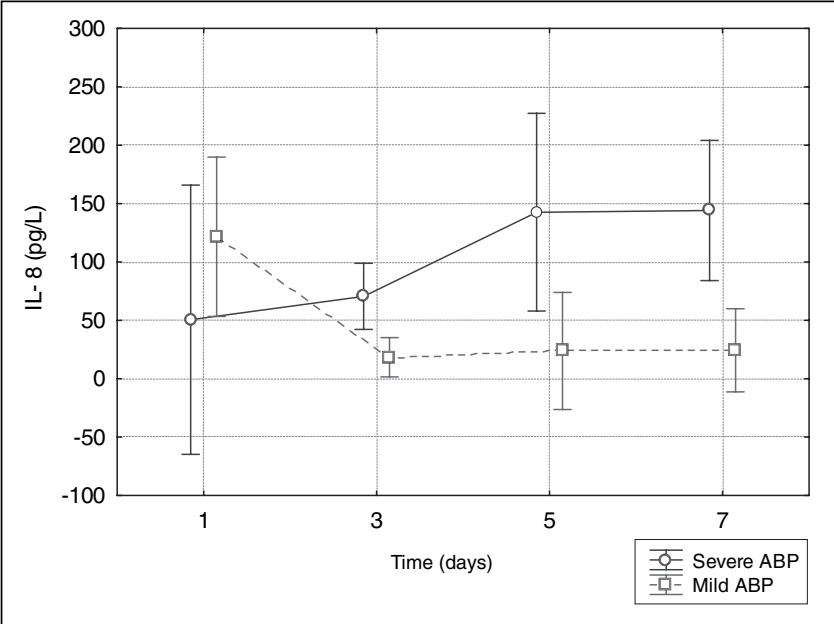

Figure 4) Serum levels of interleukin (IL)-8 in patients with mild and severe acute biliary pancreatitis $(A B P)$

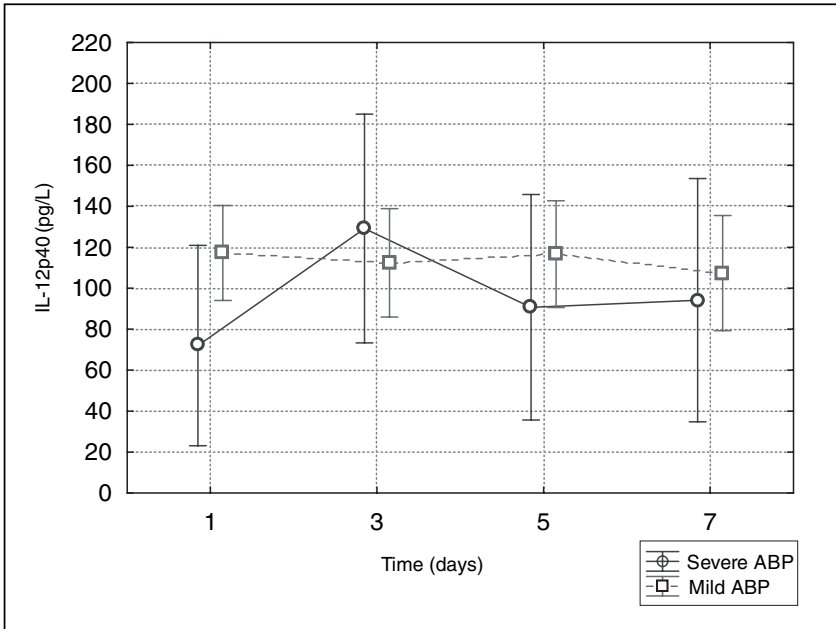

Figure 5) Serum level of interleukin (IL)-12p40 in patients with mild and severe acute biliary pancreatitis $(A B P)$

\section{DISCUSSION}

ABP, especially SABP, is linked with significant morbidity and mortality rates. At the present time, we do not have reliable laboratory tests that allow us to predict the outcome of the disease.

During the course of ABP, several types of cytokines are generated. Interpretation of the serum levels of cytokines is difficult because they have a short half-life and they coincide in the blood with cytokine inhibitors.

TNF- $\alpha$ is secreted by monocytes, macrophages, neutrophils and $T$ cells. In the present study, TNF- $\alpha$ levels were significantly higher in SABP patients than in MABP patients. Similar results have been reported in a recent study by Singh et al (8).

IL-1 $\beta$ is produced by monocytes and activated macrophages. It has a very short half-life and is often undetectable in the serum of patients with ABP. We did not find statistically significant differences in the concentration of IL-1 $\beta$ in either group of patients. Similar results were reported by Hirohita et al (5), McKay et al (6) and Mayer et al (7). 
IL-6 is a major mediator of acute-phase protein reaction. In the present study, IL-6 levels showed a peak value on the first day in both groups of patients $(5,8)$. Although the levels of IL- 6 decreased in the third, fifth and seventh days of the study in both groups, they were still significantly higher in patients with SABP than in MABP patients. Some studies report the highest levels of IL- 6 in patients with SABP during the first two to three days of the disease while other studies confirm our observations (9-11). Berney et al (11) and Norman et al (12) claimed that the serum concentration of IL- 6 on the first day was helpful in predicting the severity of ABP. It is probable that high levels of IL-6 may trigger the progression of SABP to systemic inflammatory response syndrome and MODS.

Levels of IL-6 and IL-8 measured from peripheral blood mononuclear cells were similar for patients with MABP and with SABP. "Making allowance for the white cell count revealed that IL- 6 and IL-8 release per unit of blood was significantly greater in those with severe disease" (13).

IL-8 is a potent activator of neutrophil granulocytes. Activated neutrophils infiltrate inflamed pancreatic tissue, release enzymes (proteases) and produce large quantities of free radicals of $\mathrm{O}_{2}$ that can damage cell membranes of the gland. IL-8 also promotes neutrophil migration outside the vascular bed and amplifies the inflammatory response (14). On the first

\section{REFERENCES}

1. Uhl W, Isenmann R, Buchler MW. Infections complicating pancreatitis: Diagnosing, treating, preventing. New Horiz 1998;6(Suppl 2):S72-9.

2. Schmidt S, Uhl W, Friess H, Malfertheiner P, Buchler MW. The role of infection in acute pancreatitis. Gut 1999;45:311-6.

3. Rinderknecht H. Fatal pancreatitis, a consequence of excessive leukocyte stimulation? Int J Pancreatol 1988;3:105-12.

4. Makhija R, Kingsnorth AN. Cytokine storm in acute pancreatitis. J Hepatobiliary Pancreat Surg 2002;9:401-10.

5. Hirohita M, Nozawa F, Okabe A, et al. Relationship between plasma cytokine concentration and multiple organ failure in patients with acute pancreatitis. Pancreas 2000;21:141-6.

6. McKay CJ, Gallagher G, Brooks B, Imrie CW, Baxter JN. Increased monocyte production in association with systemic complications in acute pancreatitis. Br J Surg 1996;83:919-23.

7. Mayer J, Rau B, Gansague F, Beger HG. Inflammatory mediators in human acute pancreatitis: Clinical and pathophysiological implications. Gut 2000;47:546-52.

8. Singh K, Narang AP, Singh RP, et al. Evaluation of the prognosis role of inflammatory markers. Tumor necrosis factor (TNF-) and interleukin-6 (IL-6) in patients with acute pancreatitis. Indian J Surg 2003;65:480-2.

9. Chen CC, Wang SS, Lee FY, Chang FY, Lee SD. Proinflammatory cytokines in early assessment of the prognosis of acute pancreatitis. Am J Gastroenterol 1999;94:213-8.

10. Scholmerich J. Interleukins in acute pancreatitis. Scand J Gastroenterol Suppl 1996;219:37-42.

11. Berney T, Gasche Y, Robert J, et al. Serum profiles of interleukin-6, interleukin-8, and interleukin-10 in patients with severe and mild acute pancreatitis. Pancreas 1999;18:371-7.

12. Norman JG, Fink GW, Debham W, et al. Tissue-specific cytokine production during experimental acute pancreatitis. A possible mechanism for distant organ dysfunction. Dig Dis Sci 1977;42:1783-6. day of the present study, serum levels of IL-8 were similar in both groups of patients. In the following days, IL-8 levels significantly increased in patients with SABP and subsequently decreased in the MABP group.

IL-12p40 is secreted by peripheral lymphocytes. It stimulates the proliferation of human lymphoblasts. The role of IL-12p40 in ABP remains unclear. Pezzilli et al $(15,16)$ showed that IL-12p40 levels increased in patients with ABP in comparison with healthy subjects. In the current study, the average level of IL-12p40 was slightly higher in patients with MABP versus in those with SABP on the day of admission. In the following days, there was no significant difference in the average concentration of IL-12p40 in the two groups of patients. As pointed out by Makhija and Kingsnorth (4), whatever the etiology of the pancreatitis, a 'cytokine storm' lies at the heart of the problem of damage in ABP. In the present study, the levels of some proinflammatory cytokines were significantly higher in MABP patients compared with SABP patients.

\section{CONCLUSION}

It is conceivable that we can improve the outcome of patients with SABP by blocking or attenuating the proinflammatory cytokines. The recent clinical trials of anticytokine therapies were disappointing, but the quest continues (23).

13. Brivet FG, Emilie D, Galanud P. Pro- and anti-inflammatory cytokines during acute severe pancreatitis: An early and sustained response, although unpredictable of death. Crit Care Med 1999;27:749-55.

14. de Beaux AC, Ross JA, Maingay JP, Fearon KC, Carter DC. Proinflammatory cytokine release by peripheral blood mononuclear cells from patients with acute pancreatitis. Br J Surg 1996;83:1071-5.

15. Pezzilli R, Billi P, Miniero R, et al. Serum interleukin-6, interleukin-8, and beta 2 -microglobulin in early assessment of severity of acute pancreatitis. Comparison with serum C-reactive protein. Dig Dis Sci 1995;40:2341-8.

16. Pezzilli R, Miniero R, Cappelletti O, Barakat B. Behaviour of serum interleukin 12 in human acute pancreatitis. Pancreas 1999;18:247-51.

17. Becker V. Pathological anatomy and pathogenesis of acute pancreatitis. World J Surg 1981;5:303-13.

18. Balthazar EJ. CT diagnosis and staging of acute pancreatitis. Radiol Clin North Am 1989;27:19-37.

19. Bradley EL III. A clinically based classification system for acute pancreatitis. Summary of the International Symposium on Acute Pancreatitis. Arch Surg 1993;128:586-90.

20. Ranson JH, Rifkind KM, Roses DF, Fink SD, Eng K, Spencer FC. Prognostic signs and the role of operative management in acute pancreatitis. Surg Gynecol Obstet 1974;139:69-81.

21. Knaus WA, Draper EA, Wagner DP, Zimmerman JE. APACHE II: A severity of disease classification system. Crit Care Med 1985;13:818-29.

22. Marshall JC, Cook DJ, Christou NV, Bernard GR, Sprung CL, Sibbald WJ. Multiple organ dysfunction score: A reliable descriptor of a complex clinical outcome. Crit Care Med. 1995;23:1638-52.

23. Krause I, Valesini G, Serivo R, Shoenfeld Y. Autoimmune aspects of cytokine and anticytokine therapies. Am J Med 2003;115:390-7. 


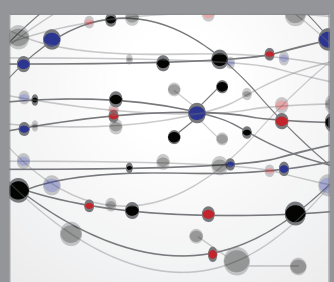

The Scientific World Journal
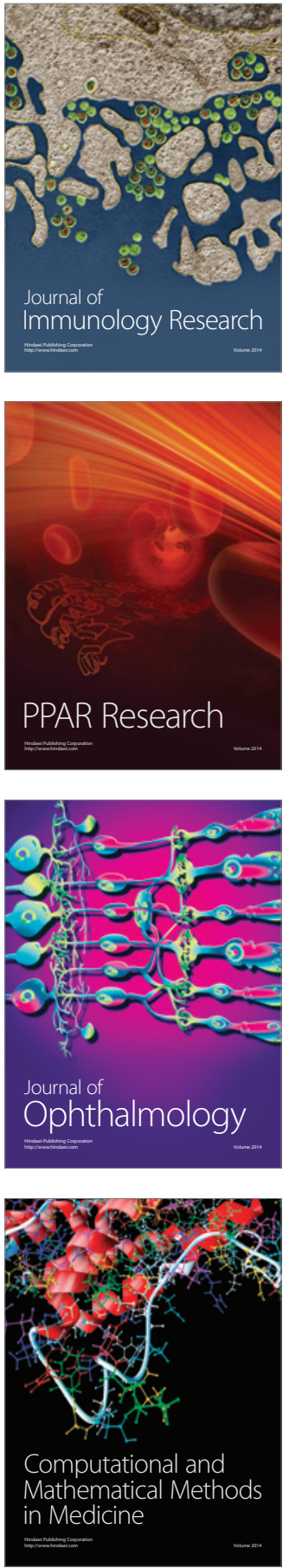

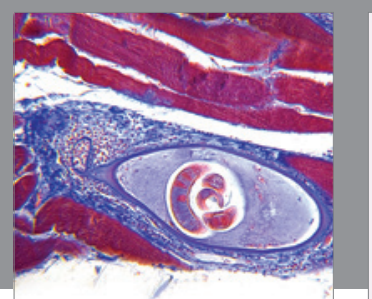

Gastroenterology Research and Practice

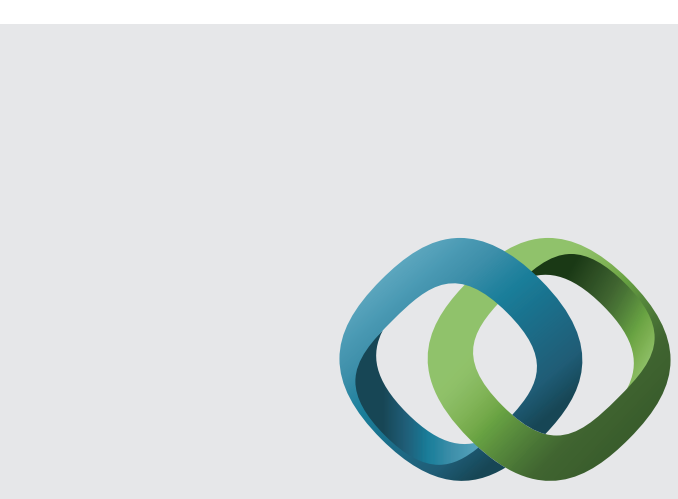

\section{Hindawi}

Submit your manuscripts at

http://www.hindawi.com
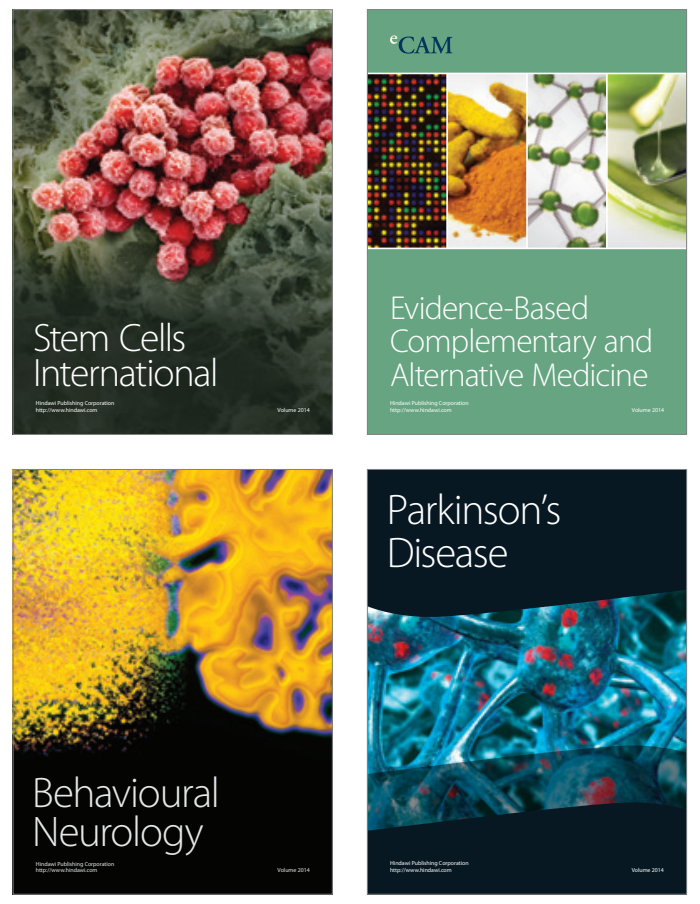
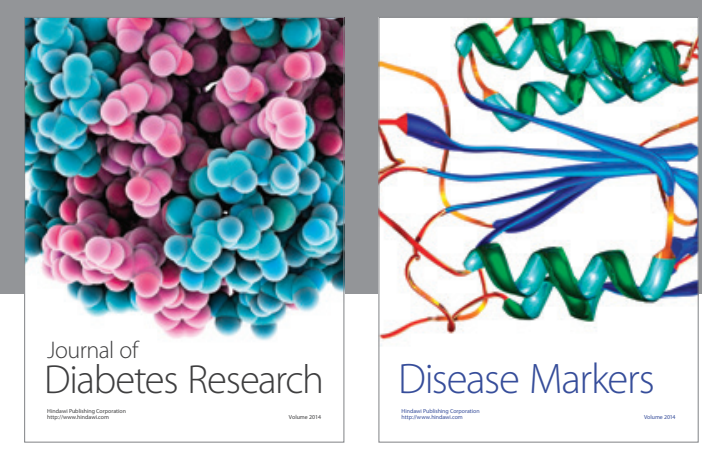

Disease Markers
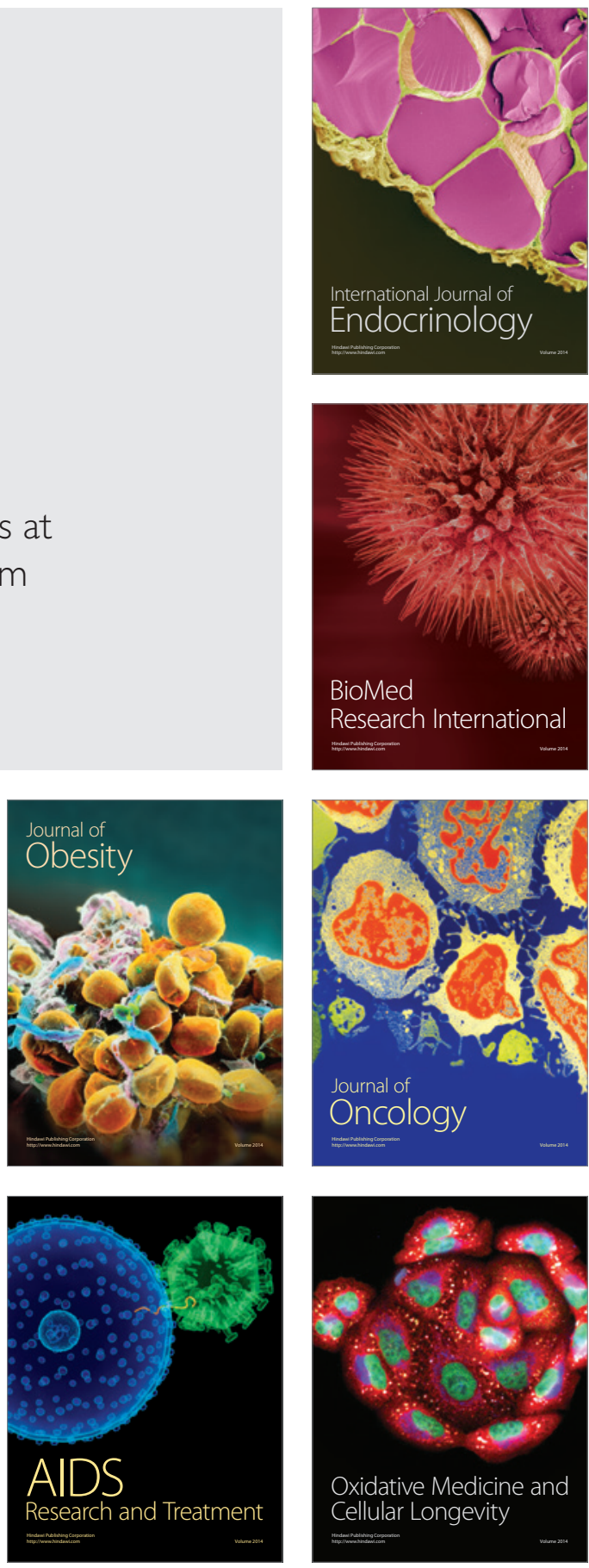